\title{
Association of Sleep paralysis with Insomnia and Sleep Quality
}

\author{
Hunniya Bint E Riaz ${ }^{1}$, Azal Ikhlaq ${ }^{1 *}$, Imtiaz Bashir ${ }^{1}$, Farhat Ijaz ${ }^{1}$, Rana Khurrum Aftab ${ }^{2}$ and Amna Ijaz ${ }^{3}$ \\ ${ }^{1}$ CMH Lahore Medical College, Pakistan
}

${ }^{2}$ Punjab Institute of Cardiology

${ }^{3}$ Sharif Medical College, Pakistan

Submission: February 19, 2021; Published: April 07, 2021

"Corresponding author: Azal Ikhlaq, CMH Lahore Medical College, Abdur Rehman Road, Lahore Cantt, Lahore, Pakistan

Abstract

Background: Sleep paralysis, accompanied by hypnopompic and hypnogagic hallucinations is commonly occurring phenomenon affecting number of individuals and it is found to be usually associated with sleeplessness and poor sleeping habits and quality.

Aims: To obtain an association between sleep paralysis and insomnia and sleep quality.

Methods: This was a cross sectional examination led on medical undergraduates in a local medical college of Pakistan. A survey containing segment data, a sleep paralysis related questionnaire, a scale for insomnia; Insomnia Severity Index and a scale for sleep quality; Pittsberg Sleep Quality Index was completed by 100 participants.

Results: Positive association was found between sleep paralysis and Insomnia and sleep quality with $\mathrm{p}=-0.11$ and $d=0.247, \mathrm{p}<0.001$ and $=-$ 0.417 respectively. Medical undergraduates have high prevalence (52.8\%) of sleep paralysis. Also, the high rate of occurrence among the females than males and higher rates in adolescents are particularly of concern.

Conclusion: There is a positive association between frequency of occurrence of sleep paralysis and insomnia and sleep quality. Better sleep schedules, enhancement of sleep quality with possible eradication of insomnia should be done in order to prevent terrible experience of sleep paralysis.

Keyword: Sleep paralysis; Insomnia; Sleep quality

Abbreviations: SP: Sleep Paralysis; REM: Rapid Eye Movement; ISP: Isolated Sleep Paralysis; ISI: Insomnia Severity Index; PSQI: Pittsberg Sleep Qualty Index; USEQ: Unusual Sleep Experience Questionnaire

\section{Introduction}

Sleep paralysis (SP) is a neurophysiological occurrence triggered by transitory desynchrony in the infrastructure of rapid eye movement (REM) sleep. As far as elaboration of SP is concerned, it may be characterized as "concise intercepts of incapacity to locomote, to communicate and also to open one's eyes on arousing (hypnapompic or postdormital SP) or maybe more infrequently when going to sleep, this whole event has a similarity with REM, may be due to the presence of control centers in the pons which are basically responsible for causing muscle atonia and other features of REM sleep. The incidence rate of SP is $5-62 \%$ and so is rather a commonly occurring phenomenon. Since most suffered people have solitary or sporadic occurrence of SP, it can be repetitive, or may take place in conjunction with narcolepsy. When SP does not occur with any other malady such as narcolepsy, it is called isolated sleep paralysis (ISP). ISP events were intricate and frequently exteroceptive occurrences and after assessing a preponderance of symptoms they usually accompany clinically important echelon of fright/anguish.
The various groups of people suffering from it, $7.6 \%$ of it includes the general population, $28.3 \%$ of students, and $31.9 \%$ of psychiatric patients. Purposes behind elevated rates in the last two populaces are fairly hazy, however could be because of components, for example, a higher recurrence of rest disturbances, use of various kinds of drugs, and more factor rest plan [1]. To the extent dynamic rest factors, more horrendous rest quality has been found in various examinations to be connected with extended odds of SP. Likewise, a sleeping disorder side effects, insomnia (yet not an analyzed a sleeping disorder issue) have additionally been found to anticipate SP. Treatment nonremitters (who don't transmit with psychotherapy) had altogether more regrettable emotional rest quality and essentially raised phasic REM as estimated by various examinations. May be obviously, the presence and recurrence of rest loss of motion (SP) share a cozy relationship with helpless rest quality all the more by and large. Understanding the idea of this affiliation is significant both for promoting our essential agreement of SP and for the motivations 
behind creating medicines to decrease or even wipe out SP among the masses who suffer from the ill effects of it. So, the fundamental point of this examination is to locate an essential connection between SP with sleep quality and sleep deprivation (insomnia) among medical undergraduates who by and large have helpless rest wake cycles.

\section{Methodology}

\section{Study duration and study population}

A cross-sectional study with the administration of questionnaire was carried out at local Pakistani Medical College, Lahore in June and July 2020. The study population consisted of undergraduate medical students. Ethical approval from Ethical Review Board of CMH Lahore Medical College was taken prior to the conduction of study.

\section{Sample size and study design}

The example size was determined to be 100 .We mentioned 150 clinical understudies to round out our study structures and 105 consented to participate. Educated assent was taken before the filling of the structures. It was obviously referenced that none of their own data will be revealed and all the data they give will be utilized to investigate reason as it were. Moreover, they can pull out from the examination whenever they need. Any inquiries or worries of members with respect to the poll were explained in detail [2] structures were disposed of because of inappropriate filling. The collaboration rate was $85.33 \%$. Irregular examining was finished. 100 reactions were considered for the last investigation.

\section{Materials}

The questionnaire consisted of demographic information,the questionnaire on sleep paralysis and scales for Insomnia Severity Index (ISI) and Pittsberg Sleep Qualty Index (PSQI). Segment qualities included age, sexual orientation, spot of living etc.Assessment of Sleep Paralysis; its essence highlights, and recurrence, was finished utilizing Unusual Sleep Experience Questionnaire (USEQ) . This questionnaire has been used to assess sleep paralysis in USA. Side effects of a sleeping disorder were evaluated utilizing the Insomnia Severity Index (ISI) . The ISI is brief, legitimate, and solid self-report screening measure that surveys the presence, nature, and seriousness of sleep deprivation manifestations. The seven things of the ISI are appraised on a 5-point Likert scale and yield an all-out score with set up clinical short Cronbach's Alphabet of 0.92. The scale used to observe sleep quality is Pittsberg Sleep Quality Index (PSQI) having Cronbach's Alphabet of 0.82 .

\section{Statistical analysis}

The information gathered will be broke down utilizing SPSS rendition 25. Expressive insights will be introduced as mean \pm SD for quantitative factors and recurrence and rates for subjective factors. Independent t-test will be applied for examination of gathering implies. A p esteem $\leq 0.05$ will be viewed as noteworthy.

\section{Results}

Frequency and features of SP in the Sample of Investigation Fifty-two point eight(52.8\%) percent of members revealed in any event one lifetime scene of SP, and $20.8 \% \%$ of the individuals who detailed at any rate one lifetime scene had encountered one to two and roughly $20 \%$ have encountered multiple scenes during the earlier year. Among the individuals who had encountered SP, $55.3 \%$ revealed pre or post dormital illusions (visual, hearable, and material) during SP and $76 \%$ detailed it to be in a state incapable to move. For a correlation of segment qualities of SP positive and SP negative individuals, see Table 1.

\section{Sleep Paralysis and self-reported measures of ISI Symptoms and PSQI}

a) SP and ISI the $\mathrm{SP}+$ people show positive relation having $p=-0.11$ and $d=0.247$ and the rate of frequency indicating a much higher relation with $\mathrm{p}=0.02$ and $\mathrm{d}=0.227$

b) SP and PSQI the SP+ people have also reported high values of PSQI the relation being $\mathrm{p}<0.001$ and $\mathrm{d}=-0.417$ suggesting a positive relation between the two (Table 2-3).

\section{Discussion}

SP has been discovered to happen in the typical individuals $[3,4]$ and leaving with them a great deal of stress and dread prompting upset life and redirected consideration of people in their everyday life, so it is of much worry in mental circles nowadays and may be of worry to the overall population when the mindfulness will emerge about it. The outcomes indicated that the greater part roughly $52.8 \%$ answered to be SP sufferers among the ordinary people and this is exceptionally near the recently done researches [3] and further avows the possibility that of SP in typical people which is a disturbing circumstance as a result of its impacts on rest cycles and general emotional well-being of the person and among them almost $20 \%$ were found to have experienced SP more than 4 times during the past year. This high recurrence of SP asserts repeating secluded rest loss of motion and this is disturbing as the more explicit symptomatic condition of "Recurrent Isolated Sleep Paralysis" is a perceived sleep wake problem, it isn't broadly known to non-sleep trained professionals. The occasions experienced during ISP are likewise very comparable regarding pre and post dormital mind flights and failure to move which have been accounted for by $76 \%$ of the people which is portrayed as far as visual pipedreams by Hinton and partners demonstrating that roughly $90 \%$ of exceptionally damaged Cambodian Refugees have visual mental trips during a scene of SP

With regard to the demographic profile, it has been observed that sleep paralysis is present among females than males.

The higher rates of occurrence among females then males seen in current study may be due to the high stress levels in females than in males as this sample is taken from Pakistani population so the social challenges of females are far more than males leading to their high stress levels and also because SP has also been seen to 
have a direct relation with Perceived Stress. As far as the age group is concerned the higher rates of SP is observed many times during teenage followed by many dreadful illusions which again affirms the anxiety among the adolescents. With regards to the discipline of study MBBS students generally show high frequency of occurrence of sleep paralysis as compared to the other professions which is possibly due to the disturbed schedule and poor sleep wake cycle of MBBS students which is also indicated in former literature [5] as compared to the students of other disciplines. The relationship between sleep paralysis and insomnia (self-measured using ISI), it has been shown to be positive which is in accordance with the previous literature [6]. A relationship between Insomnia and Depression has been observed. Since the downturn patients for the most part show significant levels of pressure thus report restlessness or daytime dozing achieving an ever-increasing number of scenes of rest loss of motion.

Moreover, many studies have suggested a relationship of sleep paralysis with REM [7] and REM is usually accompanied by a low level of sleep as shown by delta waves on EEG. Anyway, along with affiliation another highlight note is the event of rest loss of motion over the previous month and past year is huge. This high recurrence of event of SP is especially of worry as this gives the possibility of Recurrent Isolated Sleep Paralysis as it is perceived as a rest wake disorder [8]. Treatments which diminish sleep deprivation or potentially broad sleep disruptions might be useful for mitigating ISP [2]. The PSQI shows a positive relationship of SP and sleep quality which is likewise in conjunction with past literature [3]. This affiliation can be advocated by the recently done research [5] demonstrating helpless rest quality to be connected with high phasic REM and REM rest has an immediate relationship with rest loss of motion as appeared by recently done researches $[7,9]$. Study limitations and recommendations. In this study selfreported measures are taken for insomnia and sleep quality, but a better relation can be found out using clinically diagnosed insomnia. Clinical trials should be done [10-19].

\section{Conclusion}

ISP scenes were perplexing and frequently multisensorial encounters, and most of surveyed indications were related with clinically critical degrees of dread/trouble. Striking mental trips of others and substances were basic also. It is suggested as well that ISP be evaluated when sufferers informs about apparently odd encounters. Also, a positive connection has been found among SP and ISI and PSQI. So, the endeavors ought to be made to eliminate the overall side effects of a sleeping disorder and to have sound rest in order to wipe out this rest loss of motion problem.

\section{References}

1. Hishikawa Y, Shimizu T (1995) Physiology of REM sleep, cataplexy, and sleep paralysis. Advances in neurology 67: 245-271.
2. Dahlitz M, Parkes JD (1993) Sleep paralysis. The Lancet 341(8842): 406-407.

3. Goode GB (1962) Sleep paralysis. Archives of Neurology 6(3): 228-234.

4. Denis D (2018) Relationships between sleep paralysis and sleep quality: current insights. Nature and science of sleep 10: 355-367.

5. Lima PF, Medeiros AL, Araujo JF (2002) Sleep-wake pattern of medical students: early versus late class starting time. Brazilian Journal of Medical and Biological Research 35(11): 1373-1377.

6. Buysse DJ, Tu XM, Cherry CR, Begley AE, Kowalski J, et al. (1999) Pretreatment REM sleep and subjective sleep quality distinguish depressed psychotherapy remitters and nonremitters. Biological psychiatry 45(2): 205-213.

7. Knybel PW, Juchnowicz HK, Flis M, Rog J, Hinton DE, et al. (2020) Prevalence and Clinical Picture of Sleep Paralysis in a Polish Student Sample. International Journal of Environmental Research and Public Health 17(10): 3529.

8. Hinton DE, Hufford DJ, Kirmayer LJ (2005) Culture and sleep paralysis. Transcultural Psychiatry 42(1): 5-10.

9. Sharpless BA, Kliková M (2019) Clinical features of isolated sleep paralysis. Sleep medicine 58: 102-106.

10. Sateia MJ (2014) International classification of sleep disorders. Chest 146(5): 1387-1394.

11. Sharpless BA, Barber JP (2011) Lifetime prevalence rates of sleep paralysis: a systematic review. Sleep medicine reviews 15(5): 311-315.

12. Paradis C, Friedman S, Hinton DE, McNally RJ, Solomon LZ, et al. (2009) The assessment of the phenomenology of sleep paralysis: The Unusual Sleep Experiences Questionnaire (USEQ). CNS neuroscience \& therapeutics 15(3): 220-226

13. Bastien CH, Vallières A, Morin CM (2001) Validation of the Insomnia Severity Index as an outcome measure for insomnia research. Sleep medicine 2(4): 297-307.

14. Buysse DJ, Reynolds III CF, Monk TH, Hoch CC, Yeager AL, et al. (1991) Quantification of subjective sleep quality in healthy elderly men and women using the Pittsburgh Sleep Quality Index (PSQI). Sleep 14(4): 331-338.

15. Sharpless BA (2016) A clinician's guide to recurrent isolated sleep paralysis. Neuropsychiatric disease and treatment 12: 1761-1767.

16. Rosenfield S (1980) Sex differences in depression; Do women always have higher rates. Journal of health and Social Behavior 1: 33-42.

17. Xue Y, Li Q, Zhao L, Jia J, Feng L, et al. (2016) Analysis of Teens Chronic Stress on Micro-blog. In International Conference on Web Information Systems Engineering pp. 121-136.

18. Szklo-Coxe MA, Young T, Finn L, Mignot E (2007) Depression: Relationships to sleep paralysis and other sleep disturbances in a community sample. Journal of sleep research 16(3): 297-312.

19. Brunner DP, Dijk DJ, Tobler I, Borbély AA (1990) Effect of partial sleep deprivation on sleep stages and EEG power spectra: evidence for nonREM and REM sleep homeostasis. Electroencephalography and clinical neurophysiology 75(6): 492-499. 


\section{Your next submission with Juniper Publishers will reach you the below assets}

- Quality Editorial service

- Swift Peer Review

- Reprints availability

- E-prints Service

- Manuscript Podcast for convenient understanding

- Global attainment for your research

- Manuscript accessibility in different formats

( Pdf, E-pub, Full Text, Audio)

- Unceasing customer service

Track the below URL for one-step submission https://juniperpublishers.com/online-submission.php 